\title{
LEACHING AND DECAY RESISTANCE OF ALDER AND PINE WOOD TREATED WITH COPPER BASED WOOD PRESERVATIVES
}

\author{
Ali Temiz ${ }^{1, \star}$, Gry Alfredsen², Umit C. Yildiz ${ }^{1}$, Engin D. Gezer ${ }^{1}$, Gaye Kose', \\ Selcuk Akbas ${ }^{3}$, Sibel Yildiz ${ }^{1}$.
}

\begin{abstract}
The objective of this study was to determine the leaching and decay resistance of Alder (Alnus glutinosa subsp. barbata) and Scots pine (Pinus sylvestris) wood samples treated with copper based preservatives. Samples were treated with CCA, ACQ, Tanalith E and Wolmanit with different concentrations. Scots pine samples were exposed the mini-block test against brown rot fungi (Poria placenta) and Coniophora puteana while alder wood samples were tested against brown rot fungi (Coniophora puteana) and white rot fungi (Coriolus versicolor). Regarding to leaching test, treated samples were impregnated with 300 $\mathrm{ml}$ of distilled water and after 6,24, 48 and thereafter at 48-hour intervals, the leachate was removed and replaced with fresh distilled water according to AWPA E11. Samples of each leachate were collected and retained for copper analysis. Amount of copper released from treated wood during the leaching test was chemically analyzed with Atomic Absorption spectroscopy. Perchloric acid procedure for the digestion of wood was used according to AWPA A7-97. The amount of copper component ( $Q d$ ), the cumulative quantities leached $(Q c)$ and the average daily fluxes $(F L U X)$ were calculated. Results shows that CCA treated samples release less copper compared to other copper based preservatives used in this study. Highest mass losses were obtained from the leached samples treated with 1\% of ACQ-2200 against decay fungi.
\end{abstract}

Keywords: Copper based wood preservatives, wood protection, Alder, Scots pine, leaching of copper.

\section{INTRODUCTION}

Wood is susceptible to decay by wood destroying organisms. Wood preservatives are used to treat wood to extend the service life, mainly when wood is used in outdoors applications and/or in hazardous environment. Water-borne preservatives are widely employed in the wood treatment industry. Chromated copper arsenate (CCA) has been used as a major wood preservative for many applications such as utility poles, children's playgrounds, residential and commercial applications. CCA solutions contain chromium, arsenic and copper in the form of oxides or salts. Chromium is present as hexavalent chromium but it is reduced to trivalent chromium in the treated wood while arsenic is pentavalent and copper is curic oxide. Inorganic pentavalent arsenic and hexavalent chromium $\left(\mathrm{Cr}^{\mathrm{VI}}\right)$ are classified hazardous to the environment and to humans (Cui 2004, Hingston et al. 2001, Shibata et al. 2007, Townsend et al. 2004, Townsend et al. 2005, Moghaddam and Mulligan 2008, Lin et al. 2009).

\footnotetext{
${ }^{1}$ Karadeniz Technical University, Faculty of Forestry, 61080 Trabzon, Turkey

${ }^{2}$ Norwegian Forest and Landscape Institute, Høgskoleveien 8, Ås, Norway

${ }^{3}$ Artvin Coruh University, Faculty of Forestry, 08000 Artvin, Turkey

Received: 20.12. 2012 Accepted: 22.04. 2013

Corresponding author: ‘temiz@ktu.edu.tr
} 
During the last two decades increased public concern on the risk of potential environmental contamination from CCA treating solution and CCA treated wood has lead to several researches and publications on the impact of CCA treated wood. The use of CCA treated wood has been restricted and/ or banned in some countries (Lebow and Tippie 2001, Yildiz et al. 2004, Temiz et al. 2006, Gezer 2003, Habicht et al. 2003, Jambeck et al. 2006, Townsend et al. 2001, Stilwell et al. 2003, Khan et al. 2006, Shalat et al. 2006, Gezer et al. 2006). More recently, chromium and arsenic-free new formulations of wood preservatives have being introduced as replacements for CCA in many applications. These new wood preservatives contain copper and organic co-biocides such as quaternary ammonium compounds (quats), azoles, borates and/or HDO (Hasan et al. 2010, Lebow and Tippie 2001, Zhang 1999, Hingston et al. 2001, Vasishth 1996). They also contain amine and or ammonia as solubizing and complexing agent for copper. American Wood Protection Association (AWPA) book of standard (AWPA 2008) lists several arsenic and chromium-free wood preservatives. The list includes alkaline copper quat (ACQ), Ammoniacal copper citrate (CC), Copper Azole (Tanalith E), Copper Dimethyldithiocarbamate (CDDC) etc. (AWPA 2008). Alternatives to CCA contain copper as primary active ingredients because of the excellent fungicidal properties of copper and a co-biocide to protect against copper tolerant decay fungi.

Laboratory and field test have demonstrated that new emerging arsenic and chromium free wood preservatives have good long term protection against wood destroying organisms comparable to CCA and acceptable mammalian toxicity characteristics. One of the important parameter of the mammalian toxicity and the long term biological efficacy of preservatives is its permanence in treated wood which can be assessed by measuring the amount leachable in treated wood.

The objective of this study is to estimate the permanence or migration of copper in copper based preservatives treated scots pine and alder wood with CCA as reference using leaching protocol established by AWPA and determine their biological durability against brown and white rot fungi.

\section{MATERIALS AND METHODS}

\section{Wood species and Wood preservatives}

Alder (Alnus glutinosa subsp. barbata) and Scots pine (Pinus sylvestris L.) sapwood were selected for tests. Samples were free from presence of knots, resin pockets. The densities of alder and Scots pine are 496 and $490 \mathrm{~kg} / \mathrm{m}^{3}$, respectively. Pine wood was used due to the primary commercially used wood species for softwood. Among the hardwoods, alder wood was selected because of regional abundance. The amount of alder wood in Turkey comprises around 95.103 hectares and 63.894 hectares of them is in the Northeast of Turkey (Kahveci 2012).

In the experiment, ACQ-1900 (Copper tetra-ammine- dihydrogencarbonate as active copper component), ACQ-2200 (Copper as active copper component), Tanalith E 3491 (Copper hydroxycarbonate as active copper component) and Wolmanit CX-8 (Bis-(N-cyclohexyldiazeniumdioxy)- copper (II)-HDO and copper (II) carbonate as active copper component) were chosen for treatments as chromium and arsenic free copper based preservatives. $\mathrm{CCA}$ ( $\mathrm{CuO}$ as active copper component) was also used as reference.

\section{Impregnation Procedure}

Samples were air dried at room temperature and then impregnated in a small scale impregnation container using a vacuum of $760 \mathrm{~mm}$ of $\mathrm{Hg}$ for $60 \mathrm{~min}$ followed by atmospheric pressure for $60 \mathrm{~min}$. Treated samples were then removed from the treatment solution, wiped lightly to remove solution from the wood surface, and weighed to the nearest $0.01 \mathrm{~g}$ to determine gross retentions for each cube and each treating solution. Solution concentrations utilized refer to total actives of wood preservatives. The 
retention for each treatment solution was calculated using the following equation (1):

$$
\mathrm{R}=(\mathrm{G} \times \mathrm{C} / \mathrm{V}) \times 10
$$

Where:

$\mathrm{R}$ : is the retention in $\mathrm{kg} / \mathrm{m}^{3}$

G: weight in gram of the treating solution absorbed by the samples obtained by subtracting the weight of the samples after treatment from the weight of the samples before treatment

$\mathrm{C}$ : the concentration or solution strength of the treating solution in percentage

$\mathrm{V}$ : volume of the samples in $\mathrm{cm}^{3}$

After the wood samples were treated with chemicals, the samples were then wrapped in plastic bags for three weeks at room temperature for potential fixation reactions before further testing.

\section{Leaching test}

Leaching test was performed according to AWPA E11-97 (AWPA E11 2000). Six cubes of treated wood specimens (19x19x19 mm) were impregnated with $300 \mathrm{ml}$ of distilled water, after 6, 24, 48 and thereafter at 48 -hour intervals, the leachate was removed and replaced with fresh distilled water. Samples of each leachate were collected and retained for copper analysis.

\section{Analysis of copper in treated blocks and in leachate of each leaching phase}

The amount of copper in treated wood blocks $(19 \times 19 \times 19 \mathrm{~mm})$ and in the leachate was measured by an Atomic Absorption Spectrometer (Perkin-Elmer). The leached and unleached blocks were ground into 30 mesh sawdust and acid digested for copper analysis. Perchloric acid procedure for the digestion of wood was used according to AWPA A7-97 (AWPA A-7, 1997). Ground and oven dried wood samples were digested slowly with addition of nitric acid on low heat at approximately $100{ }^{\circ} \mathrm{C}$. After no brown fumes were released from the digestion tubes, perchloric acid mixed with sulfuric acid to form acidoxidant was added.

Standard copper solutions were prepared by serially diluting a commercial $1000 \mathrm{ppm}$ standard copper solution. All the leachate and solutions from solid cubes were diluted to provide a suitable copper concentration for Atomic Absorption analysis.

Determination of cumulative quantities leached and average daily fluxes

The amount of copper in leachate was determined in parts per million (ppm). The amount of copper component ( $Q d$, eq. 2 ), the cumulative quantities leached ( $Q c$, eq. 3 ) and the average daily fluxes ( $F L U X$, eq. 4) were calculated according to equations 2,3 and 4.

$$
\begin{gathered}
Q d(\Delta t)=\left(C \cdot V_{\text {leachate }}\right) / A R E A_{\text {wood }}^{\text {exp }} \\
Q c(t i)=\sum_{j=\Delta t 1}^{\Delta t n} Q d(\Delta t)(j)
\end{gathered}
$$

$Q d(\Delta t)$ is the quantity of wood preservative element in mg per surface area of the $\left(\mathrm{mg} / \mathrm{m}^{2}\right)$,

$\mathrm{V}_{\text {leachate }}$ is the volume of leachate solution in $\mathrm{ml}(1)$,

$A R E A_{\text {wood }}^{\text {exp }}$ is the surface area of wood cubes immersed in the leaching test in $\mathrm{m}^{2}$,

$\mathrm{C}$ is the concentration of wood preservative element in the leachate solution in $\mathrm{mg}$ / Qc is the total quantity of wood preservative element leached 
FLUX $(\Delta t)$ is the total quantity of chemical (element) leached from cubes immersed in water per day in $\mathrm{mg} / \mathrm{m}^{2} \mathrm{~d}$.

\section{Decay test}

Scots pine samples $(5 \times 10 \times 30 \mathrm{~mm}(\mathrm{RxT} \times \mathrm{L}))$ were exposed to agar-block test containing $3 \%$ malt agar extract culture medium against two brown rot fungi (Postia placenta (Fries) Cook sensu J. Eriksson (FPRL 280) and Coniophora puteana (Schumacher ex Fries) Karsten (BAM Ebw. 15). The brown rot fungi was used for Scots pine samples because much timber used in construction is from coniferous species and brown rot fungi preferentially degrade softwood timber (Goodell et al. 2003). Alder wood samples $(5 \times 10 \times 30 \mathrm{~mm}(\mathrm{RxTxL}))$ were tested against one brown rot fungi (Coniophora puteana (Schumacher ex Fries)) Karsten (BAM Ebw. 15) and one white rot fungi (Coriolus versicolor (CTB 863A)).

All wood samples were sterilized by $25-50 \mathrm{kGy} \gamma$-radiation. Prior to the decay test samples were leached in water according to AWPA E11 to determine the leaching effects that would occur in service (AWPA E11, 2000). Each plate contained one treated test sample and one untreated control sample. Six replicates for each treatment were used. The incubation time was 8 weeks at $22{ }^{\circ} \mathrm{C}$ and $70 \%$ relative humidity. After incubation, the samples were removed and dried at temperature of $103 \pm 2{ }^{\circ} \mathrm{C}$, weighed and the mass loss caused by the fungus calculated as follows:

$$
\text { Mass loss }(\%)=[(\mathrm{mo}-\mathrm{md}) / \mathrm{mo}] \times 100
$$

Where mo is the oven dry mass prior to test and md is the oven dry mass after the test. 


\section{RESULTS AND DISCUSSION}

Table 1 lists the retention per wood preservatives and per wood species. Retention values shown in table 1 refer for total actives of wood preservatives tested. Alder wood showed higher chemical uptake than pine due to structural differences between softwood and hardwood species. The remaining copper $(\mathrm{CuO})$ in wood blocks after leaching test are also listed in table 1.

Table 1. Retention values and remaining $\mathrm{CuO}$ in wood.

\begin{tabular}{l|c|c|c|c}
\hline & \multicolumn{2}{c}{\begin{tabular}{c} 
Retention for \\
\multicolumn{2}{c}{ Remaining CuO }
\end{tabular}} & \multicolumn{2}{c}{$\begin{array}{c}\text { Retention for } \\
\text { Remaining CuO }\end{array}$} \\
\cline { 2 - 5 } & $\begin{array}{c}\text { alder } \\
\left(\mathrm{kg} / \mathrm{m}^{3}\right)\end{array}$ & $\begin{array}{c}\text { in alder } \\
(\%)\end{array}$ & $\begin{array}{c}\text { Pine } \\
\left(\mathrm{kg} / \mathrm{m}^{3}\right)\end{array}$ & $\begin{array}{c}\text { in Pine } \\
(\%)\end{array}$ \\
\hline CCA 1\% & $9,63(0,26)^{*}$ & 88,07 & $7,69(0,05)$ & 91,47 \\
CCA 2\% & $19,81(0,46)$ & 94,30 & $11,36(0,41)$ & 86,67 \\
ACQ-1900 2\% & $19,66(0,41)$ & 98,24 & $11,13(0,10)$ & 89,53 \\
ACQ-1900 3\% & $29,81(0,64)$ & 89,74 & $22,54(0,19)$ & 89,45 \\
ACQ-2200 $1 \%$ & $9,68(0,32)$ & 61,80 & $7,47(0,07)$ & 56,73 \\
ACQ-2200 2\% & $19,71(0,43)$ & 40,72 & $10,77(0,06)$ & 62,41 \\
Tanalith E 3491 2\% & $19,32(0,52)$ & 57,33 & $7,77(0,09)$ & 81,94 \\
Tanalith E 3491 2.8\% & $27,35(0,71)$ & 79,10 & $12,05(0,08)$ & 84,65 \\
Wolmanit CX-8 1\% & $9,66(0,25)$ & 78,95 & $7,37(0,13)$ & 87,34 \\
Wolmanit CX-8 2\% & $19,52(1,06)$ & 55,02 & $8,41(0,06)$ & 85,86 \\
\hline
\end{tabular}

* Values in parentheses indicate standard deviation

As can be seen in table 1, the highest percentage of remaining copper in wood blocks was determined from samples treated with ACQ-1900 2\% and CCA 1\% respectively for both wood species. The lowest remaining copper in wood was obtained from the samples treated with ACQ-2200 for both wood species, suggesting that migration of copper in ACQ is higher than that in CCA. The results indicates that in some cases substantially more leaching occurred from alder wood than from pine wood. Higher leaching rates in alder wood than in pine might be explained by respective differences in lignin and extractive content of species. Softwoods have higher lignin contents than hardwoods. In addition, their lignin have higher contribution of free phenyl $\mathrm{OH}$ groups, which have been considered as the most probable reaction sites for wood preservative components (Radivojevic and Cooper 2010). Researchers reported that hardwoods have higher leaching rates than softwood (Stevanovic-Janezic et al. 2001, Cooper et al. 1997, Radivojevic and Cooper 2010).

The amount of copper leached is listed in table 2. 
Table 2. Leached copper amount (CuO) (ppm).

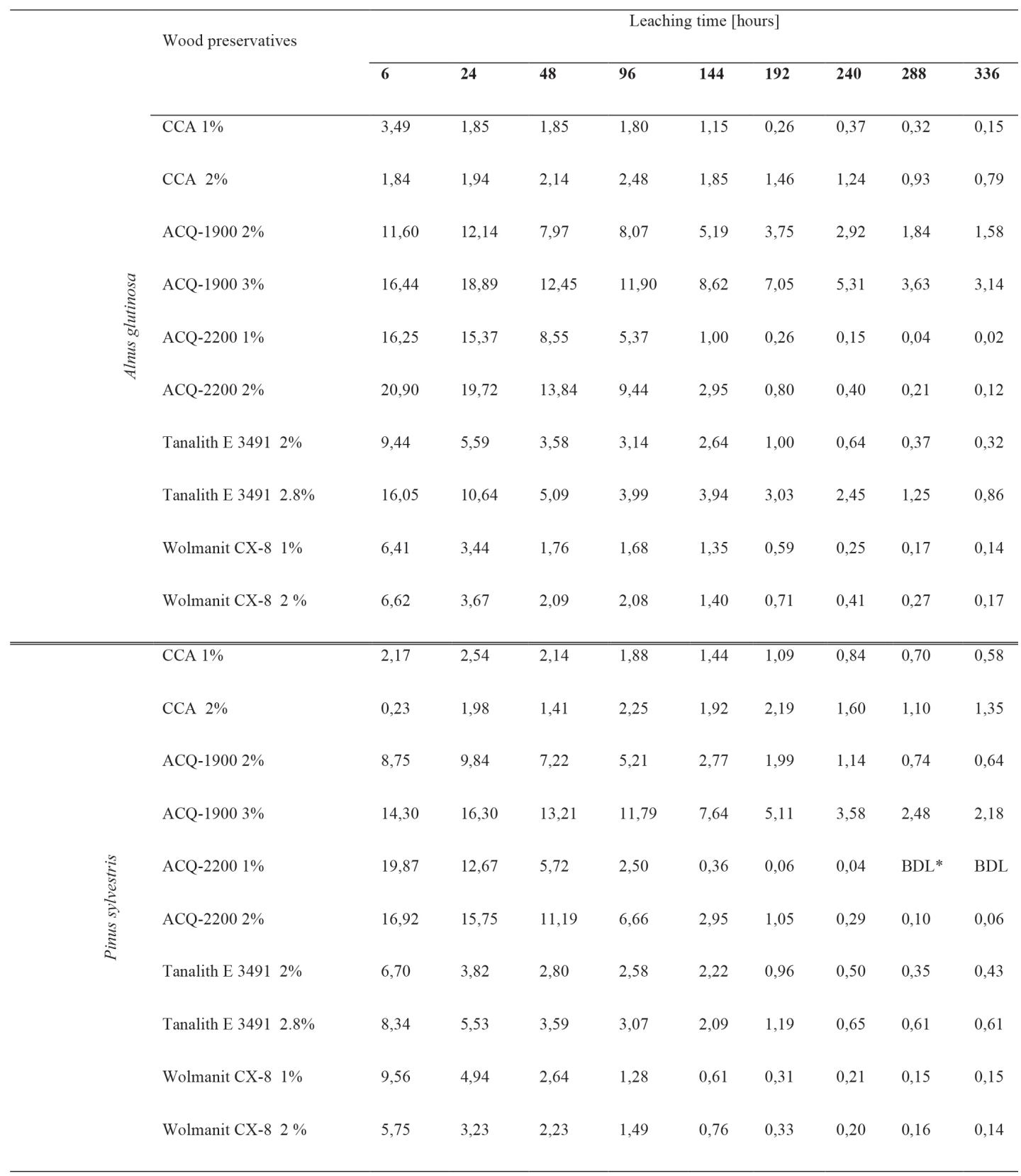

* BDL: Below the detection limit

The lowest copper amount was determined from CCA-treated wood for both wood species. The highest copper amount was obtained from the samples treated with ACQ-2200. The leaching results demonstrate that copper leaching of both wood species shows similar trends.

Using data from table 2 , the quantity of wood preservative component $(Q d)$ and total quantity leached copper $(Q c)$ have been calculated by using equations 2 and 3. Quantity of each leaching phase of wood preservative component $(Q d)$ and total quantity $(Q c)$ are listed in table 3 . 
Table 3. Quantity of copper emission of wood treated with copper based wood preservatives.

\begin{tabular}{|c|c|c|c|c|c|c|c|c|c|c|c|}
\hline \multirow{12}{*}{ 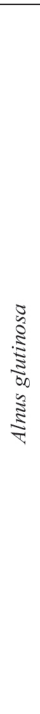 } & \multirow{2}{*}{ Wood preservatives } & \multicolumn{9}{|c|}{$\mathrm{Qd}\left(\mathrm{mg} \mathrm{m}^{-2}\right)$} & \multirow{2}{*}{$\begin{array}{l}\text { Qc (mg) } \\
\text { Total }\end{array}$} \\
\hline & & 6 & 24 & 48 & 96 & 144 & 192 & 240 & 288 & 336 & \\
\hline & CCA $1 \%$ & 80,6 & 42,7 & 42,7 & 41,6 & 26,4 & 6 & 8,5 & 7,4 & 3,5 & 259,46 \\
\hline & CCA $2 \%$ & 42,5 & 44,8 & 49,4 & 57,2 & 42,7 & 33,7 & 28,6 & 21,5 & 18,2 & 338,64 \\
\hline & ACQ-1900 2\% & 267,8 & 280,2 & 184 & 186,3 & 119,8 & 86,6 & 67,4 & 42,5 & 36,5 & 1271,01 \\
\hline & ACQ-1900 3\% & 379,5 & 436,1 & 287,4 & 274,7 & 199 & 162,7 & 122,6 & 83,8 & 72,5 & 2018,24 \\
\hline & ACQ-2200 1\% & 375,1 & 354,8 & 197,4 & 124 & 23,1 & 6 & 3,5 & 0,9 & 0,5 & 1085,18 \\
\hline & ACQ-2200 2\% & 482,5 & 455,2 & 319,5 & 217,9 & 68,1 & 18,5 & 9,2 & 4,8 & 2,8 & 1578,49 \\
\hline & Tanalith E $34912 \%$ & 217,9 & 129 & 82,6 & 72,5 & 60,9 & 23,1 & 14,8 & 8,5 & 7,4 & 616,81 \\
\hline & Tanalith E 3491 2,8\% & 370,5 & 245,6 & 117,5 & 92,1 & 91 & 69,9 & 56,6 & 28,9 & 19,9 & 1091,87 \\
\hline & Wolmanit CX-8 $\quad 1 \%$ & 148 & 79,4 & 40,6 & 38,8 & 31,2 & 13,6 & 5,8 & 3,9 & 3,2 & 364,5 \\
\hline & Wolmanit CX-8 2\% & 152,8 & 84,7 & 48,2 & 48 & 32,3 & 16,4 & 9,5 & 6,2 & 3,9 & 402,12 \\
\hline \multirow{10}{*}{ 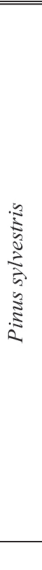 } & CCA $1 \%$ & 250,1 & 58,6 & 499,4 & 43,4 & 33,2 & 25,2 & 19,4 & 16,2 & 13,4 & 308,86 \\
\hline & CCA $2 \%$ & 5,3 & 45,7 & 32,5 & 51,9 & 44,3 & 50,6 & 36,9 & 25,4 & 31,2 & 323,87 \\
\hline & ACQ-1900 2\% & 202,0 & 227,1 & 166,7 & 120,3 & 63,9 & 45,9 & 26,3 & 17,1 & 14,8 & 884,12 \\
\hline & ACQ-1900 3\% & 330,1 & 376,3 & 304,9 & 272,2 & 176,4 & 118 & 82,6 & 57,2 & 50,3 & 1768,01 \\
\hline & ACQ-2200 1\% & 458,7 & 292,5 & 132 & 57,7 & 8,3 & 1,4 & 0,9 & BDL* & BDL & 951,52 \\
\hline & ACQ-2200 2\% & 390,6 & 363,6 & 258,3 & 153,7 & 68,1 & 24,2 & 6,7 & 2,3 & 1,4 & 1268,93 \\
\hline & Tanalith E $34912 \%$ & 154,7 & 88,2 & 64,6 & 59,6 & 51,2 & 22,2 & 11,5 & 8,1 & 9,9 & 469,99 \\
\hline & Tanalith E 3491 2.8\% & 192,5 & 127,7 & 82,9 & 70,9 & 48,2 & 27,5 & 15 & 14,1 & 14,1 & 592,8 \\
\hline & Wolmanit CX-8 $1 \%$ & 220,7 & 114 & 60,9 & 29,5 & 14,1 & 7,2 & 4,8 & 3,5 & 3,5 & 458,22 \\
\hline & Wolmanit CX-8 2\% & 132,7 & 74,6 & 51,5 & 34,4 & 17,5 & 7,6 & 4,6 & 3,7 & 3,2 & 329,87 \\
\hline
\end{tabular}

* BDL: Below the detection limit

$Q d$ represents the total quantity of copper leached out within a time interval. $Q c$ represents the total quantity of copper leached out $\left(\mathrm{mg} / \mathrm{m}^{2}\right)$. FLUX represents the average daily flux for each time interval.

The lowest quantity of copper emission $(Q d)$ from treated wood with copper based wood preservatives released was obtained from CCA treated wood, then followed by Wolmanit CX-8. The highest $Q d$ was determined from ACQ treated wood for both species.

When comparing total $(Q c)$ quantity of copper emissions, the highest copper emission was found from the wood treated with ACQ-1900 3\%, the lowest result was determined from the samples treated with CCA $1 \%$ for both species.

The daily leaching of copper $\left(F L U X\left(\mathrm{mg} / \mathrm{mg}^{2} \mathrm{~d}\right)\right.$ was calculated using data from table 4 with Eq 4 . The daily FLUX rate for both species is represented in figure 1 and figure 2. 


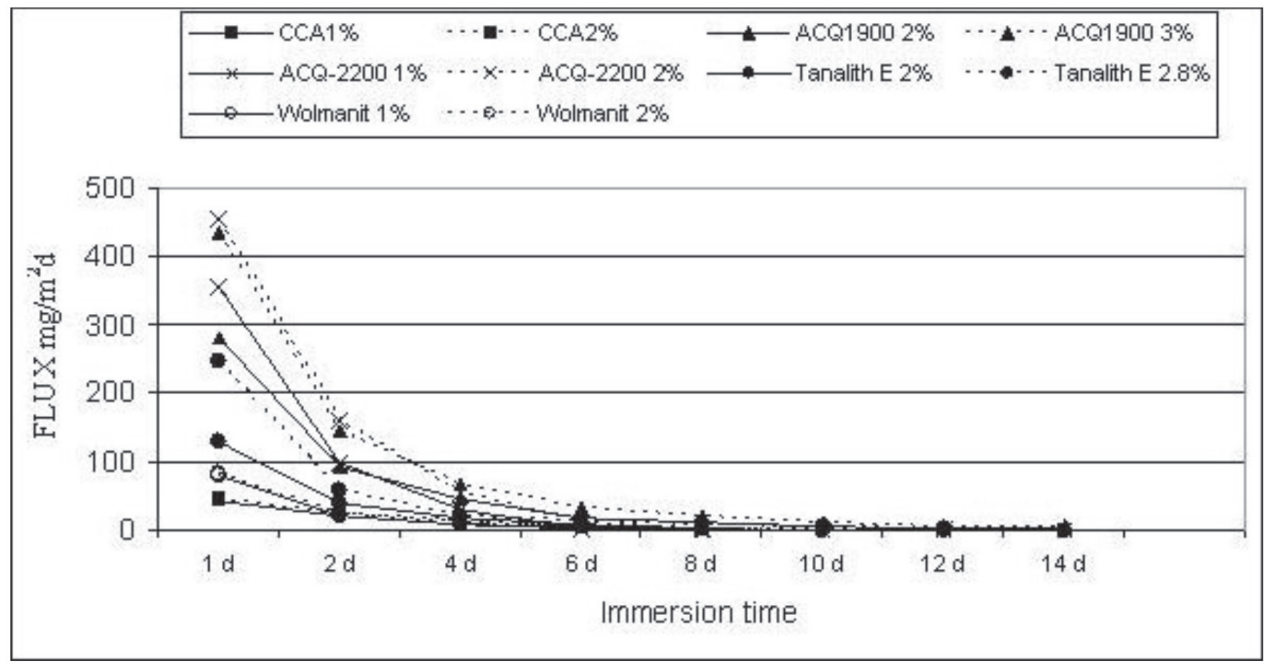

Figure 1. Total quantity of copper leached of alder wood area per $\mathrm{m}^{2}$ per day $(\mathrm{d}=$ day $)$.

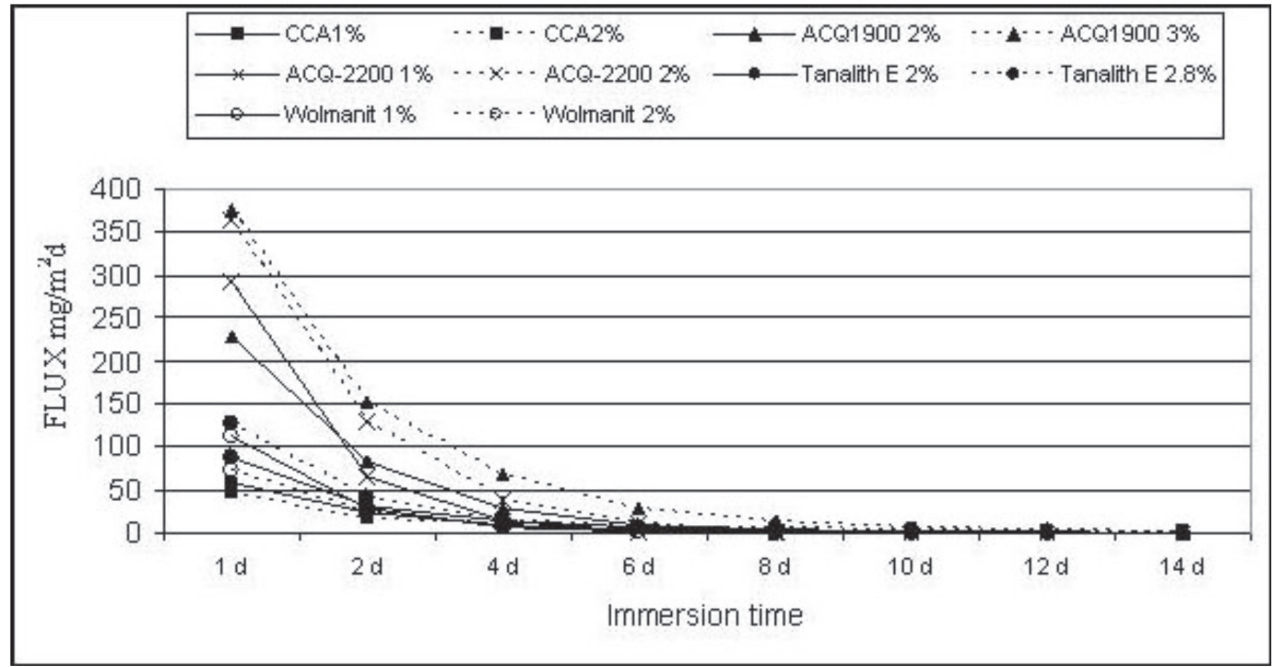

Figure 2. Total quantity of copper leached of pine wood area per $\mathrm{m}^{2}$ per day $(\mathrm{d}=$ day).

It was noticeable that the leaching rate was highest initially and rapidly decreased over time (Figure 1 and Figure 2). After the first 48 hours, the amount of copper leaching is minimal. High leaching rate at the beginning of experiment can be attributed to unfixed copper on wood surface and also the high surface area exposed to water due to the size of the testing cubes, where relatively high surface area is subjected to leaching. It is a fact that conventional short term leaching test such as AWPA E 11 and EN 84 are very aggressive compared to natural rain exposure and normal sample size of wood in service (AWPA E11 2000, EN 84 1997). Such testing using AWPA E 11 or EN 84 should not be considered representative of the reality but only comparative to give an idea of the relative permanence of several wood preservatives. 
Dubey (2005) also found that copper leached from ACQ treated wood at a rate seven times higher than the rate from CCA treated wood. Same findings have been reported by Stook et al. $(2004,2005)$ for leaching experiments. The possible explanation of less leaching rate of CCA-treated wood could be that copper in CCA is more strongly bonded and less mobile than in some of the alternative wood preservatives containing ammoniacal copper and amine copper preservatives.

The other reasons for higher copper leaching of alternative wood preservatives than CCA are the higher copper amount in alternative formulations and different fixation mechanisms. Fixation of CCA is complex process and defined by the reduction of hexavalent chromium. Multi-components of $\mathrm{CCA}(\mathrm{Cu}$, $\mathrm{Cr}$ and As) during treatment process are not simply taken up by wood components and deposited in the lumens of the cells. Copper can be found in the CCA-treated wood in four different forms: (1) $\mathrm{CuCrO}_{4}$ lignin complexes, (2) Cu2+ - lignin complexes, (3) Cu2+ - cellulose complexes, (4) Physically absorbed by various wood components (Jusoh 2000, Pizzi 1982). Unlike CCA preservative, the ammonia in new copper based systems offers an alternative method to fix copper in wood structure. Ammonia allows the solubilisation of insoluble copper component in ammonium hydroxide and causes copper component to precipitate in wood. With the ammonia evaporation, a stepwise reduction in the number of ammonia molecules bound to copper occurs and break down the complexes in solution to form water insoluble copper salt. In the amine based preservatives such as ACQ used in the study, copper fixation is through: (1) ion exchange reactions between the cupric cations and acidic functional groups such as carboxylic acid in lignin and hemicellulose, (2) complex formation with cellulose, (3) forms of insoluble copper carbonates resulting from drying process (Chen 1994, Jiang 2000).

Temiz et al. (2006) compared the copper emission rates from wood treated with CCA, ACQ, Tanalith $\mathrm{E}$ and Wolmanit CX according to OECD guidelines. Authors reported that the percentage of copper leached from wood treated with alternative copper-based preservatives was higher than that of CCAtreated wood (Temiz et al. 2006).

Townsend et al. (2001) investigated leaching and toxicity of CCA-treated and alternative-treated wood products and concluded that percentage of copper leached from the wood treated with the copper-based alternative preservatives was greater than CCA-treated wood and ACQ (Alkalen Copper Quat), CBA (Copper Boron Azole) and CC (Copper Citrate) treated wood were found to be more toxic to aquatic life forms (Townsend et al. 2001).

Habicht et al. (2003) studied the role of different parameters such as fixation, sample size and leaching protocols and reported that the lowest leaching value was found from CCA-treated wood than ACQ and CX (Copper-HDO)-treated wood (Habicht et al. 2003). This study also confirms the high leachability of copper in new formulations of copper based preservatives compared to CCA.

Weight losses of wood treated with copper based wood preservatives against brown rot (C. puteana, P. placenta) and white rot fungi (C. versicolor) are shown in table 4 and 5. 
Table 4. Decay resistance of treated with copper based Pinus sylvestris preservatives.

\begin{tabular}{|c|c|c|c|c|c|c|}
\hline \multirow[b]{2}{*}{ Wood preservatives } & \multirow{2}{*}{$\begin{array}{l}\text { Retention } \\
\left(\mathrm{kg} / \mathrm{m}^{3}\right)\end{array}$} & & \multicolumn{2}{|c|}{ Postia placenta } & \multicolumn{2}{|c|}{ Coniophora puteana } \\
\hline & & & $\begin{array}{l}\text { Weight losses } \\
(\%), \text { treated }\end{array}$ & $\begin{array}{l}\text { Weight losses } \\
(\%), \text { Control }\end{array}$ & $\begin{array}{l}\text { Weight losses } \\
(\%), \text { treated }\end{array}$ & $\begin{array}{l}\text { Weight losses } \\
(\%), \text { Control }\end{array}$ \\
\hline \multirow[t]{2}{*}{ CCA $1 \%$} & \multirow{2}{*}{$7,86(0,26)^{*}$} & Leached & $0,123(0,063)$ & $39,490(2,775)$ & $0,132(0,075)$ & $55,926(3,027)$ \\
\hline & & Unleached & $0,327(0,130)$ & $40,545(2,332)$ & $0,201(0,165)$ & $55,022(2,305)$ \\
\hline \multirow{2}{*}{ CCA $2 \%$} & \multirow{2}{*}{$16,16(0,29)$} & Leached & $0,145(0,075)$ & $38,068(2,739)$ & $0,177(0,179)$ & $51,375(3,953)$ \\
\hline & & Unleached & $0,270(0,205)$ & $43,072(5,224)$ & $0,279(0,117)$ & $49,612(4,284)$ \\
\hline \multirow{2}{*}{ ACQ-1900 2\% } & \multirow{2}{*}{$16,37(0,73)$} & Leached & $1,337(0,273)$ & $41,713(1,543)$ & $0,264(0,110)$ & $53,951(7,231)$ \\
\hline & & Unleached & $0,808(0,508)$ & $44,814(4,178)$ & $1,105(0,494)$ & $55,825(4,506)$ \\
\hline \multirow{2}{*}{ ACQ-1900 3\% } & \multirow{2}{*}{$24,53(0,45)$} & Leached & $0,911(0,146)$ & $43,856(3,004)$ & $0,327(0,102)$ & $51,426(6,421)$ \\
\hline & & Unleached & $1,511(0,250)$ & $44,036(1,686)$ & $2,523(0,454)$ & $59,438(2,567)$ \\
\hline \multirow{2}{*}{ ACQ $-22001 \%$} & \multirow{2}{*}{$8,04(0,35)$} & Leached & $20,304(1,955)$ & $36,742(3,197)$ & $19,009(4,830)$ & $54,446(4,725)$ \\
\hline & & Unleached & $5,843(1,255)$ & $46,207(2,352)$ & $1,352(1,863)$ & $54,398(3,999)$ \\
\hline \multirow[t]{2}{*}{ ACQ-2200 2\% } & \multirow{2}{*}{$16,14(0,59)$} & Leached & $4,645(1,948)$ & $42,736(4,929)$ & $1,596(2,239)$ & $53,885(5,239)$ \\
\hline & & Unleached & $1,526(0,894)$ & $50,029(4,488)$ & $1,137(0,624)$ & $51,610(2,341)$ \\
\hline \multirow{2}{*}{ Tanalith E 3491 2\% } & \multirow{2}{*}{$16,25(0,46)$} & Leached & $14,664(1,355)$ & $45,972(2,418)$ & $0,194(0,140)$ & $52,125(3,585)$ \\
\hline & & Unleached & $0,518(0,224)$ & $44,209(1,694)$ & $0,284(0,229)$ & $50,172(9,021)$ \\
\hline \multirow{2}{*}{$\begin{array}{c}\text { Tanalith E } 3491 \\
2.8 \%\end{array}$} & \multirow{2}{*}{$22,80(0,66)$} & Leached & $4,010(2,523)$ & $46,736(2,673)$ & $0,432(0,204)$ & $50,470(2,978)$ \\
\hline & & Unleached & $0,138(0,121)$ & $43,301(2,041)$ & $0,642(0,258)$ & $48,562(4,164)$ \\
\hline \multirow{2}{*}{ Wolmanit CX-8 1\% } & \multirow{2}{*}{$8,01(0,21)$} & Leached & $0,628(0,274)$ & $42,082(3,629)$ & $1,171(1,432)$ & $54,149(1,696)$ \\
\hline & & Unleached & $0,069(0,050)$ & $40,490(3,693)$ & $0,659(0,299)$ & $52,897(0,966)$ \\
\hline \multirow{2}{*}{ Wolmanit CX-8 2\% } & \multirow{2}{*}{$16,35(0,42)$} & Leached & $0,681(0,334)$ & $42,958(4,371)$ & $0,214(0,240)$ & $51,220(5,871)$ \\
\hline & & Unleached & $0,891(0,145)$ & $44,689(2,185)$ & $0,891(0,145)$ & $52,769(3,572)$ \\
\hline
\end{tabular}

* Values in parentheses indicate standard deviation 
Table 5. Decay resistance of Alnus glutinosa treated with copper based wood preservatives.

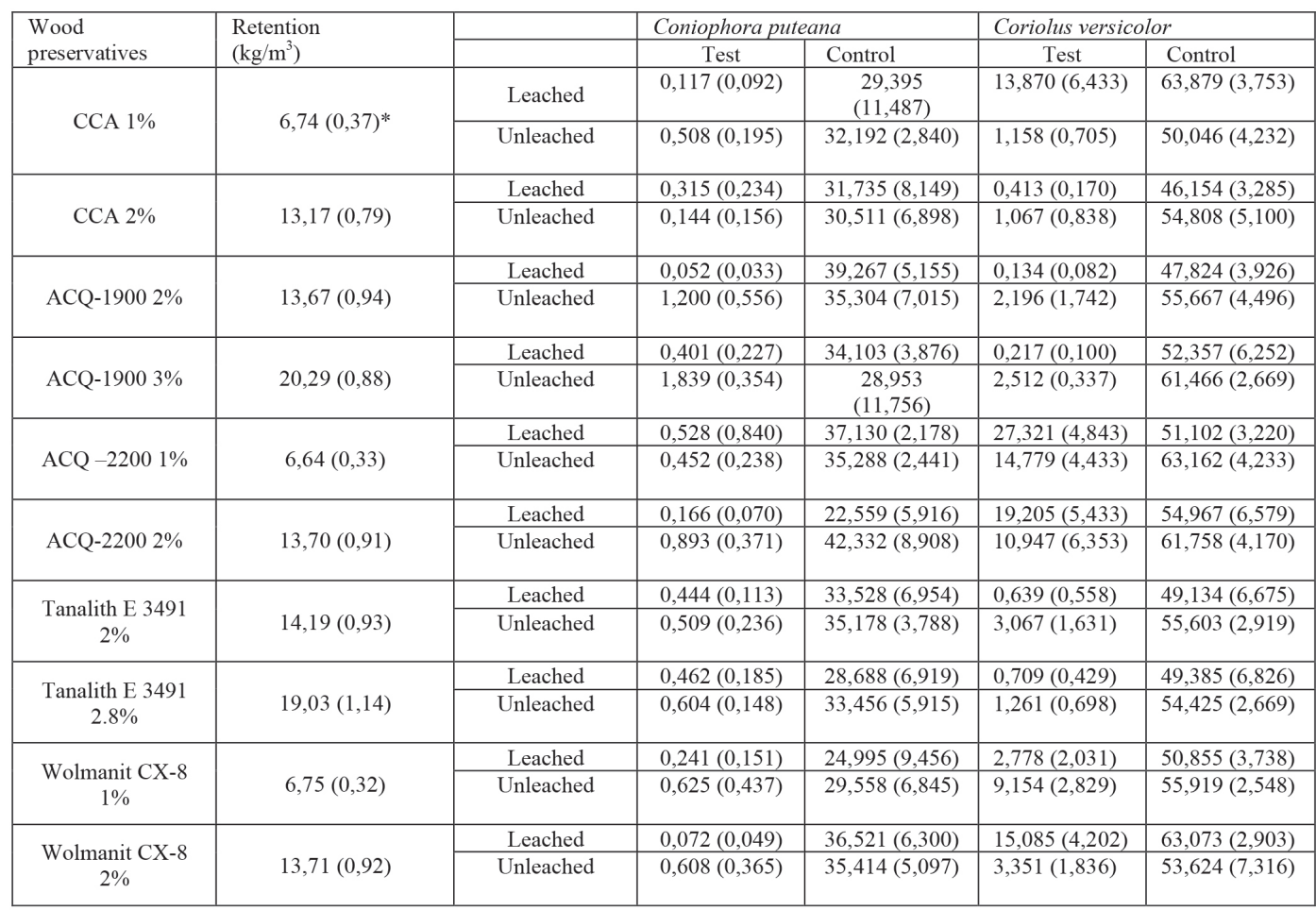

The mass loss of the control untreated samples was higher than $20 \%$ confirming the validity of test. All treated samples had lower mass loss than untreated samples. However, weight losses of leached pine wood treated with ACQ-2200 1\% and Tanalith E 3491 2\% and leached alder wood treated with ACQ2200 (1\% and 2\%) and Wolmanit CX-8 (2\%) for C. versicolor showed high mass losses (over 10\% of mass losses). The reason of high mass losses after leaching test could be due to loss of preservatives during the leaching procedure. The result of remaining copper $(\mathrm{CuO})$ in wood blocks after leaching test (Table 1) was confirmed that some of the copper based wood preservatives were much leachable then others. The possible explanations were discussed in leaching part.

\section{CONCLUSIONS}

This study compares copper leaching and decay resistance from CCA and alternative copper based wood preservatives treated Scots pine and alder wood from Eastern Turkey. Data suggest that CCA releases less copper than all the other copper based wood preservatives. Possible explanation could be due to copper in CCA is more strongly bonded than in some of the alternative wood preservatives, higher copper amount in alternative formulations and different fixation mechanisms. However, this study was performed on cubes in the laboratory tests; field test will be conducted to confirm these results.

\section{ACKNOWLEDGEMENTS}

The authors would like to thank Morten Damm, Gro Brekka, from Norwegian Wood Research Institute for technical assistance. 


\section{REFERENCES}

American Wood Protection Association Standard (AWPA A-7). 1997. Standard for wet ashing procedures for preparing wood for chemical analysis.

American Wood Protection Association Standard (AWPA E-11). 2000. Standard method of determining the leachability of wood preservatives.

American Wood Protection Association Standard (AWPA 2008). 2008. AWPA book of standards. Birmingham, AL. USA.

Chen, J. 1994. The relationship between wood temperature and fixation rate of CCA-C treated red pine sapwood. M.Sc thesis, University of Toronto, CA 117p.

Cooper, P.A.; Ung, Y.T.; Kamdem, D.P. 1997. Fixation and leaching of CCA-treated red maple (Acer rubrum L.). Forest Products Journal 47 (2): 70-74.

Cui, W. 2004. Characterization of arsenic, chromium and copper released from chromated copper arsenate type-C (CCA-C) treated southern pine. Ph.D dissertation, Michigan State Univ. Michigan, USA. 430p.

Dubey, B. 2005. Comparison of Environmental Impacts of Wood Treated with Chromated Copper Arsenate (CCA) and Three Different Arsenic-free Preservatives. Ph.D. dissertation, University of Florida, Gainesville, FL, USA. 201p.

European committee for standardization, EN . 1997. Wood preservatives- Accelerated ageing of treated wood prior to biological testing- Leaching procedure. En 84/1997. Brussels.

Gezer, E.D. 2003. The Investigation on Remediation of Out of Service CCA Treated Utility Poles, Ph.D Dissertation, Karadeniz Technical University, Graduate School of Natural and Applied Science, Trabzon, Turkey. 425p.

Gezer, E.D.; Yıldız, U.; Yıldız, S.; Dizman, E.; Temiz, A. 2006. Removal copper, chromium and arsenic from CCA-treated yellow pine by oleic acid. Building and Environment 41 (3): 380-385.

Goodell, B.; Nicholas, D.D.; Schultz, T.P. 2003. Wood deterioration and preservation: Advances in our changing world. ACS Symposium Series, 845, USA

Habicht, J.; Hantzschel, D.; Wittenzellner, J. 2003. Influence of different fixation and ageing procedure on the leaching behavior of copper from selected wood preservatives in laboratory trials. International Research Group on Wood Protection Annual Conference, IRG/WP 03-20264, 18-23 May, Stockholm, Brisbane, Queensland, Australia.

Hasan, R. A.; Hu, L.; Solo-Gabriele, H.; Fieber, L.; Cai, Y.; Townsend, T.G. 2010. Field-scale leaching of arsenic, chromium and copper from weathered treated wood. Environmental Pollution 158 (5): $1479-1486$.

Hingston, J.A.; Collins, C.D.; Murphy, R.J.; Lester, J.N. 2001. Leaching of chromated copper arsenate wood preservatives: a review. Environmental Pollution 111 (1): 53-66. 
Jambeck, J.; Townsend, T.; Solo-Gabriele, H. 2006. Leaching of chromated copper arsenate (CCA)-treated wood in a simulated monofill and its potential impacts to landfill leachate. Journal of Hazardous Materials 135 (1-3): 21-31.

Jiang, X. 2000. Fixation chemistry of amine-copper preservatives. Ph.D dissertation, University of British Colombia, CA. 255p.

Jusoh, I.B. 2000. Microdistribution of chromated copper arsenate preservative in rubberwood (Hevea brasiliensis. Arg). Ph.D dissertation, Michigan State Univ. Michigan, USA. 130p.

Kahveci, E. 2012. Effects to some physical and mechanical features of black alder (Alnus glutinosa subsp. barbata (C.A. Mey.) Yalt.) wood of different site conditions, KTU, The Graduate School of Natural and Applied Sciences, M.Sc Thesis, Trabzon, Turkey. 133p.

Khan, B.; Solo-Gabriele, H.; Townsend, T.; Cai, Y. 2006. Release of arsenic to the environment from CCA-treated wood: part I - Leaching and speciation during service. Environmental Science and Technology 40 (3): 988-993.

Lebow, S.T.; Tippie, M. 2001. Guide for minimizing the effect of preservative-treated wood on sensitive environment. United States Department of Agriculture, Forest Service, Forest Products Laboratory Madison, WI.

Lin, L.D.; Chen, Y.F.; Wang, S.Y.; Tsai, M.J. 2009. Leachability, metal corrosion and termite resistance of wood treated with copper based preservative. International Biodeterioration and Biodegradation 63 (4): 533-538.

Moghaddam, A.H.; Mulligan, C.N. 2008. Leaching of heavy metals from chromatted copper arsenate (CCA) treated wood after disposal. Waste Management 28 (3): 628-637.

Pizzi, A. 1982. The chemistry and kinetic behavior of $\mathrm{Cu}-\mathrm{Cr}-\mathrm{As} / \mathrm{B}$ wood preservatives, II.Fixation of the $\mathrm{Cu} / \mathrm{Cr}$ system on the wood. Journal of Polymer Science: Polymer Chemistry Edition 20 (3): 707-724.

Radivojevic, S.; Cooper, P.A. 2010. The effects of wood species and treatment retention on kinetics of CCA-C fixation reactions. Wood Science and Technology 44 (2): 269-282.

Shalat, S.L.; Solo-Gabriele, H.; Fleming, L.E.; Buckley, B.T.; Black, K., Jimenez, M.; Shibata, T.; Durbin, M.; Graygo, J.; Stephan, W.; Van De Bogard, G. 2006. A pilot study of children's exposure to CCA-treated wood from playground equipment. Science of the Total Environment 367 (1): 80-88.

Shibata, T.; Solo-Gabriele, H.; Fleming, L.E.; Cai, Y.; Townsend, T.G. 2007. A mass balance approach for evaluating leachable arsenic and chromium from an in-service CCA-treated wood structure. Science of the Total Environment 372 (2-3): 624-635.

Stevanovic-Janrzic, T.; Cooper, P.A.; Ung, T. 2001. Chromated copper arsenate preservative treatment of North American Hardwoods Part 2. CCA leaching performance. Holzforshung 55 (1): 7-12.

Stilwell, D.; Toner, M.; Sawhney, B. 2003. Dislodgeable copper, chromium and arsenic from CCA treated wood surface. Science of the Total Environment 312 (1-3): 123-131.

Stook, K.; Dubey, B.; Ward, M.; Townsend, T.; Bitton, G.; Solo-Gabriele, H. 2004. An evaluation of the heavy metal toxicity of pressure treated wood leachates with MetPLATE. Bulletin of Environmental Contamination and Toxicology 73 (6): 987-994. 
Stook, K.; Tolaymat, T.; Ward, M.; Dubey, B.; Townsend, T.; Solo-Gabriele, H.; Bitton, G. 2005. Relative leaching and aquatic toxicity of pressure-treated wood products using batch leaching tests. Environmental Science and Technology 39 (1): 155-163.

Temiz, A.; Yıldız, U.C.; Nilsson, T. 2006. Comparison of copper emission rates from wood treated with different preservatives to the environment. Building and Environment 41 (7): 910-914.

Townsend, T.; Dubey, B.; Tolaymat, T.; Solo-Gabriele, H. 2005. Preservative leaching from weathered CCA-treated wood. Journal of Environmental Management 75 (2): 105-113.

Townsend, T.; Stook, K.; Ward, M.; Solo-Gabriele, H. 2001. Leaching and toxicity of CCA-treated and alternative-treated wood products, Florida Center For Solid and Hazardous Waste Management, Report \#01-XX . USA

Townsend, T.; Tolaymat, T.; Solo-Gabriele, H.; Dubey, B.; Stook, K.; Wadanambi, L. 2004. Leaching of CCA treated wood: implications for waste disposal. Journal of Hazardous Materials 114 (1-3): 75-91.

Vasishth, P. 1996. Factors influencing the interactions and permanency of copper in wood. Ph.D dissertation, Mississippi State Univ., Mississippi, USA. 139 p.

Yıldız, U.C.; Temiz, A.; Gezer, E.D.; Yıldız, S. 2004. Effect of wood preservatives on mechanical properties of yellow pine (Pinus sylvestris L.) wood. Building and Environment 39 (9): 1071-1075.

Zhang, J. 1999. Interactions of copper-amine preservatives with southern pine. Ph.D dissertation, Michigan State Univ. Michigan, USA. 140p. 